\title{
The effect of stimulus-response complexity on the reaction time of schizophrenics
}

ATHAN KARRAS ${ }^{1}$

OHIO STATE UNIVERSITY

To determine if the slower performance of schizophrenics is due to slower data processing, the reaction times (RT) of schizophrenic and non-schizophrenic psychiatric Ss (controls) were compared on a simple and two-choice jump RT task. Schizophrenics were slower than controls on both tasks; the slope of the schizophrenics was flatter than the controls. The latter finding indicated that the slower performance of the schizophrenics was not due to processing data more slowly than controls.

A recent general explanation for the psychological deficit in schizophrenics implicates the data-processing system of the central nervous system (CNS), which organizes incoming data for orderly sequential presentation to higher levels of the CNS (e.g., Chapman \& McGhie, 1962; Harwood \& Naylor, 1963; Yates, 1966). Two important functions of data processing a re response selection and short-term memory storage. Chapman \& McGhie believe that the short-term memory system is defective. Yates holds that the deficit lies in the abnormally slow rate at which information is processed.

Current studies, however, confound short-term memory storage with processing rate. The present investigation attempted to determine if the processing rate of schizophrenics is defective compared to other psychiatric patients. A simple reaction time task and a two-choice RT task were used. If the deficit is one of slower processing time in selecting the appropriate response for a stimulus, then schizophrenics, compared to controls, must (a) be slower on both tasks, and (b) must have a greater difference between the two tasks (steeper slope). The latter outcome follows from the fact that a sequential matching process between stimulus and response is used in a choice RT task when choice RT is slower than simple RT.

\section{Subjects}

One hundred-thirty-four male psychiatric patients hospitalized for no less than three consecutive years and having a final diagnosis of schizophrenia constituted the schizophrenic population. All were on psychotropic drugs, but none was on sedatives.

Fifty-four male psychiatric patients with no more than 7 months of total hospitalization and having a final diagnosis of other than schizophrenia constituted the control group. Twenty-four Ss were on psychotropic drugs, excluding sedatives. Neither group had Ss with any known CNS involvement, e.g., brain surgery, primary mental deficiency or CNS injury. The age range for both groups was $18-55$ years.

\section{Apparafus}

A full description of the apparatus is found in Karras (1962). Present modifications were (a) time intervals between stimuli and the sequence of response lights for the two-choice task were electrically controlled, (b) the distance between the start button to either telegraph key which controlled a light signal was 9 in., and (c) release of a start button prior to the illumination of a response light prevented the latter from flashing on.

Briefly, mounted on a horizontal board were a start button, on which $\mathrm{S}$ rested his middle finger, and two telegraph keys. A vertical panel attached to the board housed three lights all at the same height and about eye-level for $\mathrm{S}$. The middle light was the ready signal. On either side of the ready signal was a response light. Depression of the right telegraph key turned off the right light and the left key the left light. A Standard Electric timer was activated by the onset of the response light; the timer was also deactivated by the depression of the appropriate key.

The appearance of a response light was $2,3,4$, or 5 sec. after the onset of the ready signal which lasted $.3 \mathrm{sec}$. Selection of one of the preparatory intervals (PI) was determined in a quasi-random fashion. The response light stayed on until $S$ struck the appropriate key. Selection of either response light for the twochoice task was also determined in a quasi-random manner. The interval between the offset of a response light and the appearance of the ready signal was $8 \mathrm{sec}$.

\section{Procedure}

$S$ was instructed to turn off the response light as quickly as possible. E demonstrated the jump response three times. The simple task was given first to one-half of the Ss of each group, followed by the complex task, while the conditions were reversed for the other half. For each condition $S$ was told what to expect.

Thirty RT trials followed the instructions for either condition. A $1 \mathrm{~min}$. rest period separated the conditions. The first 21 trials of each condition were considered practice trials. A median of the last nine trials was taken as S'S RT score for that condition. RT was measured in .01 sec.

\section{Results}

The mean age of the schizophrenics ( 41.0 years) was significantly greater $(p<.001)$ than of the controls (31.6 years). The mean education of the schizophrenics (10.2 years) was significantly less $(p<.001)$ than of 
Table 1. Means and Error Variances* of Combined Groups of $\mathbf{T}$ by $D$ Interaction

\begin{tabular}{lccc} 
Group & & Schizophrenic & Control \\
\hline \multirow{2}{*}{ Task } & Simple & 85.39 & 67.58 \\
& Complex & 89.83 & 74.79 \\
\hline
\end{tabular}

* MS error (between) $=102.49 . M S$ error $($ within $)=11.71$.

Df error in both cases $=182$.

the controls (12.7 years). Both differences were evaluated by $t$ tests. However, within each group there was no significant correlation between age or education and simple or complex RT score. The average length of hospitalization for the schizophrenics was 10.3 years; for the controls 29.8 days.

A $\log$ transformation of the data was necessary to eliminate heterogeneity of variance, as determined by $\mathrm{F}$ max tests, and a tendency for larger means to have larger variances. A preliminary analysis of RT scores between controls on drugs and those not on drugs showed them to be highly similar in all respects; these two subgroups were combined for subsequent analysis.

A 2 by 2 by 2 analysis of variance for repeated measures was performed on the transformed scores. Diagnosis (D) and task order (O) were between factors; type of task (T) was the within factor. It was found that diagnosis, type of task and the $\mathrm{T}$ by $\mathrm{D}$ interaction were all significant at $p<.001$. Inspection of the means associated with the interaction shows that the slope for the schizophrenics is flatter than for the controls; for each group RT on the simple task was faster ( $p<.01$ in each case), and controls were faster than schizophrenics on either task ( $p<.005$ for either task). ${ }^{2}$ Table 1 presents the means and error variances of the $\log$ scores of the groups on both tasks for the $T$ by $\mathrm{D}$ interaction. The characteristic of the $\log (-1)$ is dropped, and the mantissa is multiplied by 100 .

The error rate for all groups was virtually zero. Discussion

The present study does not support the hypothesis that the rate of processing data for schizophrenics is generally slower than for other psychiatric patients. It may be found, however, that psychiatric patients in general process data more slowly than normals. Then again this defect may appear only under special conditions, such as extended practice. In either case, care must be taken in determining whether to attribute the disability to the illness or to hospitalization.

Why the chronically ill are slower than patients acutely ill remains a problem. In part it may be the outcome of prolonged institutionalization. The data indicate that age and education are not important factors. Studies on this issue must take into account the greater arousal (drive) level at the resting state found in many of the chronic patients (Shakow, 1962; Venables, 1963). Thus, greater response competition due to greater drive could as easily account for a poorer performance, as well as a steeper slope, of schizophrenic groups as could a defect at the dataprocessing level or at any other CNS level. Broen \& Storms (1966) discuss the conditions under which high drive facilitates competing responses.

\section{References}

Broen, W. E., Jr., \& Stoms, L. H. Lawful disorganization: the process underlying a schizophrenic syndrome. Psychol. Rev., $1966,73,265-279$.

Chapman, J., \& McGhie, A. A comparative study of disordered attention in schizophrenia. J. ment. Sci., 1962, 108, 487-500.

Harwood, E., \& Naylor, G. F. K. Nature and extent of basic cognitive deterioration in a sample of institutionalized mental patients. Aust. J. Psychol., 1963, 15, 29-36.

Shakow, D. Segmental set. Arch. gen. Psychiat., 1962, 6, 1-17.

Venables, P. H. Selectivity of attention, withdrawal, and cortical activation. Arch. gen. Psychiat., 1963, 9, 74-78.

Yates, A. J. Data-processing levels and thought disorder in schizophrenia. Aust. J. Psychol., 1966, 18, 103-117.

\section{Notes}

1. The author is grateful to Dr. H. R. Albrecht of VA hospital, Chillicothe, and to Dr. D. H. Burk of Harding Hospital for the use of the patients at their respective institutions.

2. A similar analysis of variance with raw scores also failed to find a steeper slope for the schizophrenic group. The slopes of the two groups were parallel $(F$ for $T$ by $D$ interaction $=1.19$ ). 